\title{
The Status of Professional Practice Skills of Social Work Students in Vietnam
}

\author{
Nguyen Huu Long \\ Vietnam Youth Academy, Ho Chi Minh City, Vietnam \\ Email address: \\ huulongnguyen77@gmail.com
}

\section{To cite this article:}

Nguyen Huu Long. The Status of Professional Practice Skills of Social Work Students in Vietnam. American Journal of Applied Psychology. Vol. 9, No. 3, 2020, pp. 77-82. doi: 10.11648/j.ajap.20200903.14

Received: May 26, 2020; Accepted: June 9, 2020; Published: June 20, 2020

\begin{abstract}
Social workers need to have certain skills to provide the best services for their clients. Therefore, assessing the status of professional practice skills of social work students in practice is a necessary task that can help managers of training institutions to have timely accurate information on the quality of training to change and adjust to improve the quality of training. On the other hand, the results of the research on practical skills of social work students will also help schools to review the connection and orientation between training institutions and the actual requirements of professional activities. This study aims to discover the status of professional practice skills of social work students in Vietnam. 174 students studying social work at the Colleges of Social Work in Thua Thien Hue, Soc Trang, Hanoi, and Ho Chi Minh City participated in the survey. A questionnaire and a situational judgement test are used to survey the performance of professional practice skills of social work students during their internship. The results of the study show that performance of professional practice skills of social work students during the internship initially is quite well. The professional practice skills performed best by students are the client access and assessment and self-test and self-assessment skills. The skills that students did not perform well are connecting resources and making support plans. Therefore, the academic subjects related to client support services should be paid more attention to in the training program. The author also recommends that training institutions strengthen exchanges between social work experts and students to help students improve their professional skills.
\end{abstract}

Keywords: Status, Professional Practice Skills, Social Work

\section{Introduction}

Training to meet social requirements and international integration is a long-standing policy of the country's education. However, a worrying fact is that Vietnamese higher education in general and the training disciplines according to the criteria of practice are increasingly failing or meeting very low requirements of employers. With the goal of fundamental and comprehensive innovation in higher education in Vietnam in the 2006-2020 period, it has clearly stated that higher education needs to apply advanced methods to develop training programs to meet social needs and international integration. Theoretical training should be associated with professional practice [1]. To this end, training institutions have been trying to innovate curriculum, teaching methods, and connect with related businesses to help students to form vocational skills timely. Therefore, professional practice is considered as the key task in training.
Social work, a specific career field - is both theoretical and practical. Farley and Smith state that "social work is an art, a science, a profession that helps people to solve personal, group (especially family), and community problems and to attain satisfying personal, group, and community relationships through social work practice" [2] Vayda and Bogo affirm that social work students often experience the disconnection between classroom and practicum, and frequently experience difficulty in applying concepts learned in the classroom to practice [3]. Therefore, social work graduates need to have the scientific knowledge of the field and at the same time be able to perform professional skills. If professional skills are formed well at schools through classroom study or the process of self-training to prepare for a future career, they will be useful for students, employees, and employers. However, Munro shows that social work students cannot explicitly and systematically apply any relevant theory when they work with clients unless practice 
supervisors provide a clear theoretical framework [4]. In the skills-training activities for learners, practice is both the best training activity and the best practice of assessing the real situation of real-life skills because students have to apply theoretical knowledge learned in the classroom into real work with the help of the trainer.

\section{A Brief Literature Review}

\subsection{Concepts of Professional Practice Skills of Social Work Students}

The concept of social work practice has been developed based on a review of domestic and foreign studies from the operational point of view. This is an important basis from which to combine with the concept of skills to build a complete concept of professional practical skills of social work students. Thus, the concept of professional practice skills of social work students is approached based on the concept of professional practice of social work in combination with the available concept of skills [5]

Welford states that skills are organised and coordinated activities about an object or situation in ways that underlie performance [6]

Trevithick et al. define skills as interventions through which learning is put into practice [7]

Various definitions of social work can be found. However, according to Cree, "it is almost impossible to find a single definition of social work with which everyone is likely to agree"[8]. Thompson states that "social work is what social workers do" [9]. Rwomire and Raditlhokwa point out that social work as a helping profession, is in a state of crisis which revolves around issues and problems pertaining to its meaning, character and the role it plays in society [10]

Regarding skills in social work, according to Morales, Sheafor and Scot, "skills in social work simply mean the social worker's ability to set in motion with client intervention processes of change based on social work values and knowledge in a situation relevant to the client" [11]

Based on the concepts of skills, professional practice skills, social work, and characteristics of social work students, the author defines professional practice skills in the internship as follows:

Professional practice skills of social work college students in the internship are the ability to apply knowledge and experience into the performance of tasks to achieve the goals and tasks of social work students.

Professional practice skills of social work college students are social skills in general that are applied to the specific situation of students such as studying in their university environment, communicating with their lecturers, friends, and other activities. On the other hand, professional practice skills are also shown through individual learning activities, study groups, and practice activities of the subjects.

Professional practice skills have the following characteristics:

First, professional practice skills of social work are the application of professional knowledge of social work to successfully solve practical tasks of the profession. The theoretical knowledge that social students need to have is a complete and accurate understanding of duties, working conditions, client support system, or client group; the process of evaluating support activities. Based on that, students have just acquired professional practice skills, which are the ability to perform social work tasks effectively.

Second, professional practice skills of social work are associated with social work activities and only formed in the process of practicing, and working processes of individuals. To form and develop professional practice skills of social work, students must make an effort to practice in the process of professional practice in schools and continue to perfect these skills while working at the social organizations.

Third, professional practice skills of social work are an important component of occupational competence, an expression of the professional capacity of people working in the field of social work and community security. When assessing the occupational competence or professional performance of social workers and social establishments, it is evaluated through professional practice skills themselves.

The formation and development of professional practice skills of social work takes place in the process of apprenticeship, especially the practice of social students in the internship. Based on professional knowledge learned, under the guidance of lecturers, students of social work apply them into practice to assist clients or client groups and form professional skills.

\subsection{Demonstration of Professional Practice Skills of Social Work}

Since the project was implemented in a short time, the research team did not sudy professional practice skills of social work related to the process of practicing community development. To ensure the science and practicality of the survey process as well as to verify professional practice skills and measures to improve professional practice skills for college students of social work, the author proposes some professional practice skills focusing on the process of social work of individuals and some related to social work process of groups.

1. Information collection and processing skills: are the skills of social work students to apply knowledge and experience into acquiring, recording, processing and coding information of clients, groups and the community to generalize the problem most in need of assistance

2. Client (or client group) access and assessment skills: are the skills social work students to apply knowledge and experience into getting information of their client (or the group of clients) and making an initial assessment of their client (or the group of clients) to have initial assumption for client support

3. Skills to identify and solve problems are the skills that social work students apply knowledge and experience into identifying their client's (or the group of clients) main problems to have solutions for effective support.

4. Skills to connect resources and make support plans: are the skills that social work students apply knowledge and 
experience in finding related resources to timely support for their clients.

5. Self-test and self-assessment skills: are the skills that social work students apply knowledge and experience in assessing the effectiveness of the client support process and self-assessment of their competence after every support to improve their professional skills.

\section{Research Methodology and Methods}

Participants: 174 students studying social work in Capital Universities, Ho Chi Minh City College of Central Pedagogy, Soc Trang Community College, Hue Pedagogy College, Hanoi College of Technology and Trading.

Research methodology: The questionnaire and situational judgement test are used to survey the contents related to the study to demonstrate social work practice skills and the SPSS software is used to process the collected data.

Assessment criteria: The assessment is based on 3 characteristics of professional practice skills (namely correctness, maturity, sustainability). Calculate the mean scores of all 3 criteria to evaluate the performance of skills on a rating scale with 4 levels (Poor- Average- GoodExcellent). Also, the study also uses a situational judgement test, each situation has 4 options for choosing to show 4 levels (Poor- Average- Good- Excellent).

Calculation method: Mean scores and standard deviation were calculated. Based on the calculated interval coefficient for three intervals in four points $(4-1=3)$, intervals with the range of 0.75 were arranged. Specifically, from 1.00 to 1.75 : Poor; from 1.75 to 2.50: Average; from 2.51 to 3.25: Good; from 3.26 to 4.00 : excellent

\section{Results and Discussion}

In this study, the author will select the five most important skills in the process of professional practice and internship of social works students

\subsection{Status of Professional Practice Skills of Social Work Students}

Table 1. Status of professional practice skills of social work.

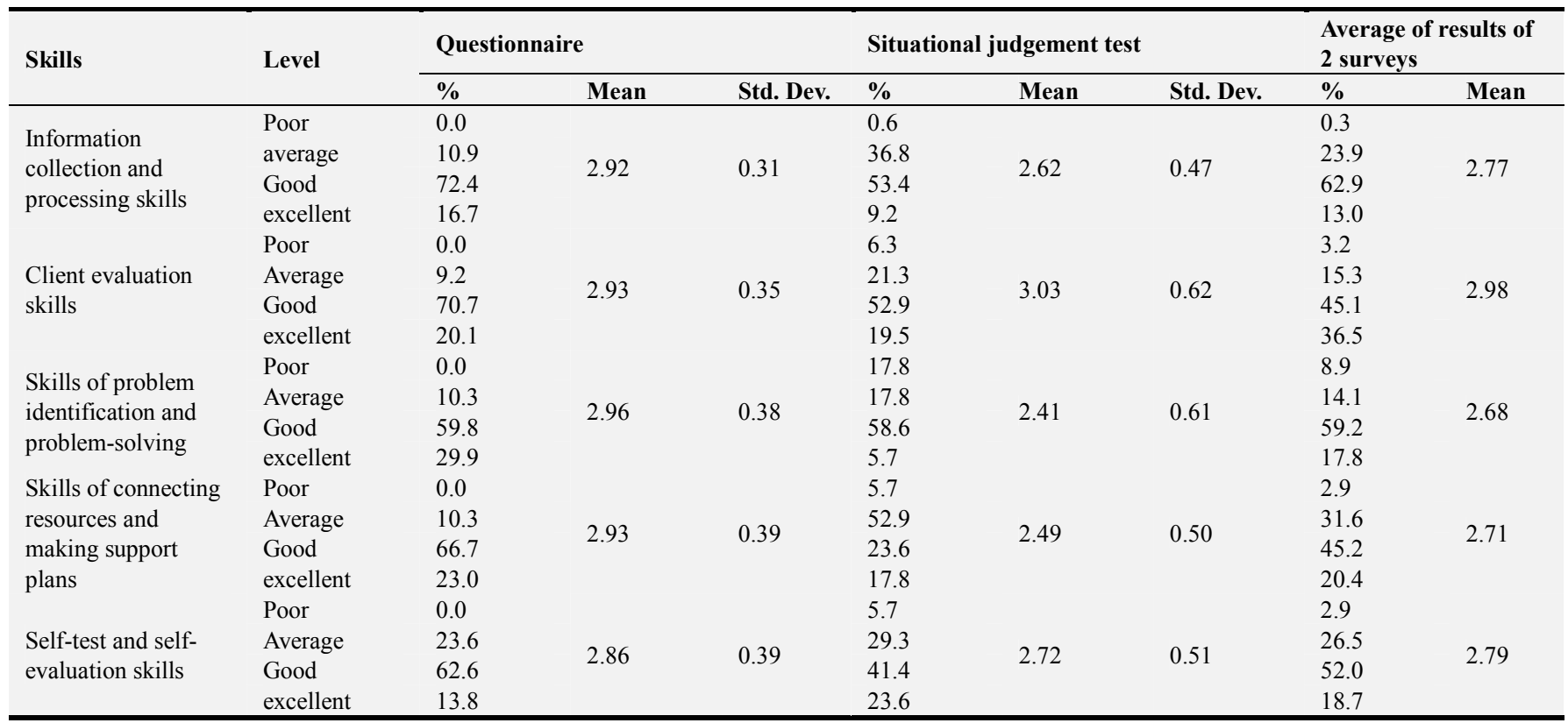

The data displayed in Table 1 show that there are differences between the two instruments (questionnaires and situational judgement test), in which the most difference are skills of problem identification and problem solving (The questionnaire is 3.20 - the good level in the rating scale but a situational judgment of 2.52 - the average level in the rating scale). The skills that have the similarities between the two instruments are the self-test and self-evaluation skills, the results are average. This result shows that, with the questionnaire, students only need to answer according to their subjective opinions, so among skills of professional practice skills of social work, all groups of participants responded very well, but with situational judgment test, the target groups showed their limitation in professional practice skills. Although there was a difference between the responses to the two surveys; however, the difference was not significant because the mean scores of the responses were little changed and the assessment level remained unchanged. The "good" level is the level with the most objects in the assessment of professional practice skills. Among four levels of skills assessment included in the study, the "excellent" level in all skills is very low. The "excellent" level of the self-test and selfevaluation skills only accounted for $23 \%$. The survey results also show that most of the research subjects have had professional practice skills, but they have not met the requirements of trainers. However, it also shows that training institutions, to some extent, have paid attention to the development of career skills for students. Students of social work have had a proper awareness of professional practice skills. 
They know how to do it and can bring out good results for their clients as well as for real jobs. They can fulfill the tasks of the final internship.

Evaluating professional practice skills of college students in Social Work. The results in Table 1 show that the skills that students perform best are the client evaluation skills with the means scores in the two surveys, respectively, which are 2.93 and 3.03, "good" level in the rating. Within the scope of this study, the client evaluation skills are considered as the initial assessment skills for students to approach their clients to identify the problems of the clients and create a friendly, close environment for the clients to express their problems. This skill shows the cohesion between students and clients. Besides, the skills also focus on maintaining the relationships with clients, supporting clients if necessary. The situational judgment test focuses on examining the capacity to create a friendly atmosphere in the first meeting with the client, how to evoke, grasp the problems or create an opportunity for the client to tell their problems. Explaining the reason why these skills are well implemented by the students of Social Sciences, a student of Ho Chi Minh City College of Central Pedagogy said, "since we have learned a lot of subjects related to the evaluation of others such as psychology, communication skills,... besides, 2 subjects of practice methods of social work by group and individual help us a lot in observing, communicating, and creating sympathy with the clients. The results of the survey and the opinions of the interviewees show that, if students want to have practical skills, including evaluation skills, it is necessary to enhance practical subjects. The skills that students of social work do not perform well are identifying and solving problem skills with a mean score of 2.68. They are also the skills with a big difference between the two surveys, respectively, the mean score for the questionnaire is 2.96 but the situational judgement test has a mean score of 2.41. This result shows that there is inconsistence in the answers of the subjects. It means that when evaluating the students' theoretical knowledge, the student answered quite well, but dealing with real situations, they did not have the right choice for solutions. Interviewing the trainer H.T.T.Q at SOS children's village school, he said, "During the internships, most of the students just stopped at the level of realizing the problem the client had in the process of talking and asking. However, they have not explained the reason why and they have not come up with the corresponding solutions. The students know their capacity, so when they found out the problem of the client, they often reported me to help them find a solution". This remark shows that students of social work at the college level have poor skills in connecting the theory and practice. They have practical skills, but they cannot apply the theoretical knowledge they have learned to explain the problems. In other skills, the skills that the student performed fairly well are self-test and self-evaluation skills. The mean scores are 2.86 and 2.72 which belong to the good level on the rating scale. This result is relevant and consistent with the clientevaluation skills. It is the college-level training program that focuses on practical orientation, so the evaluation process is always taken seriously by teachers and become a model for students to follow. Lecturer T.T.T.T - Open University of Ho Chi Minh City said: "... evaluation is very important for students of social work. In the process of teaching, I always instruct students to self-assess their learning results, selfevaluate problems, and explain reasonable causes. During the internship, the evaluation is conducted very seriously by the trainers and instructors to create good habits and also train students' self-evaluation skills". With the two other skills, students of social works perform relatively well.

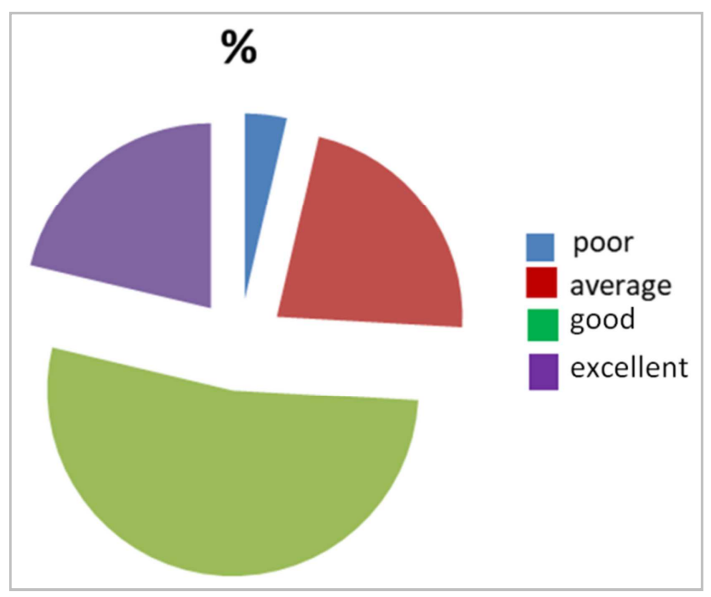

Figure 1. Percentage of level of professional practice skills.

The results in Figure 1 show that the level that students of social work can perform accounting for the majority is good. The level with the least options is poor. This is a positive result for the training of social work at the college level in the surveyed schools. With 03 years of study, the final internship is the time when students have to show what they have learned to apply in doing the assigned tasks. The good level proves that students have been able to perform professional practice skills. Students initially know their roles, responsibilities and identify their tasks with professional activities. Students know how to implement the first phase of the skills fairly well and more or less brought positive effects for their clients. With the results of skills implementation of students of the social work at training institutions at the college level, the Social Work Specialist H.C.B - Director of child care center said, "With this survey result, the training institutions can initially assure of their training quality. However, at the end of the internship period, this means that students are about to become a social worker, but a few students are achieving the "excellent" level. Therefore, training institutions should change their way of training. They should provide students with more professional practice. With specialized subjects, they should send students to social work organizations to practice before finishing the subjects". This idea is worth the attention of social training schools to adjust their curriculum, teaching methods or assessment methods to help students with better professional practice skills.

According to Nguyen Van Luc, to become a professional social worker, in addition to learning the theoretical knowledge, students need to enhance professional practice skills, not just relying on the internship [12]. Training 
institutions should identify professional practice skills frameworks following the output standards of the training program so that they have measures to improve the professional practice skills for students. The initial survey results only focused on 05 professional practice skills that are most clearly expressed in the final internship as well as the actual teaching at schools reflect truthfully and objectively professional practice skills of students. Some related research works of other authors such as Pham Thi Tam in the study "Practice, internships of Social Work students - the problems raised" or the study "Teaching student coaching activities of Social worker at the establishments - the problems raised" (Mai Kim Thanh \& Nguyen Van Giang). Or the author Nguyen Thi Hoai Yen in the article "Training human resources for social work education" and some other authors share the same opinion that social work is a new field in Vietnam, therefore, training institutions usually face problems of training programs and human resources. The studies all affirmed that building a training program towards capacity development, skills for learners is very important for students of social work [13].

\subsection{The Correlation Among Professional Practice Skills of Social Work}

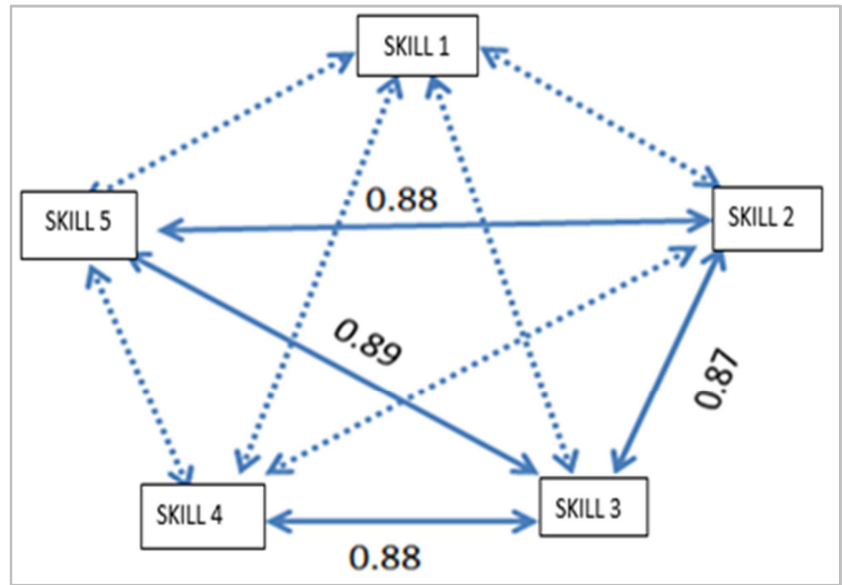

Figure 2. The correlation between professional practice skills of social work.

Table 2. The correlation among professional practice skills of social work.

\begin{tabular}{|c|c|c|c|c|c|c|c|}
\hline No. & Skill & Coefficient & Skill 1 & Skill 2 & Skill 3 & Skill 4 & Skill 5 \\
\hline \multirow{2}{*}{1} & \multirow{2}{*}{ Skill 1} & $\mathrm{r}$ & 1.000 & 0.82 & 0.72 & 0.65 & 0.80 \\
\hline & & $\mathrm{p}$ & 1.000 & 0.00 & 0.00 & 0.00 & 0.00 \\
\hline \multirow{2}{*}{2} & \multirow{2}{*}{ Skill 2} & $\mathrm{r}$ & 0.82 & 1.000 & 0.87 & 0.82 & 0.88 \\
\hline & & $\mathrm{p}$ & 0.00 & 1.000 & 0.00 & 0.00 & 0.00 \\
\hline \multirow{2}{*}{3} & \multirow{2}{*}{ Skill 3} & $\mathrm{r}$ & 0.72 & 0.87 & 1.000 & 0.88 & 0.89 \\
\hline & & $\mathrm{p}$ & 0.00 & 0.00 & 1.000 & 0.00 & 0.00 \\
\hline 4 & Skill 4 & $\mathrm{r}$ & 0.65 & 0.82 & 0.88 & 1.000 & 0.80 \\
\hline \multirow{2}{*}{5} & \multirow{2}{*}{ Skill 5} & $\mathrm{r}$ & 0.80 & 0.88 & 0.89 & 0.80 & 1.000 \\
\hline & & $\mathrm{p}$ & 0.00 & 0.00 & 0.00 & 0.00 & 1.000 \\
\hline
\end{tabular}

The results of table 2 and figure 2 show that the skills have close correlation. This shows that when one skill increases or decreases, it will have the impact on the increase or decrease of other skills. One skill with a low mean score will lead to the low mean score of other skills, and vice versa. When comparing the results of correlation pairs between skills, there is a heterogeneous correlation. Some skill pairs are strongly correlated, but there are also skill pairs that are less correlated. Typically, the pair of skills are closely related such as skills of collecting and processing information with skills of self-test and selfevaluation, the correlation is 0.89 (equivalent to $89 \%$ ). These results show that, in the process of professional practice skills, if one skill is well performed, other skills will also have better performance results. Among 5 professional practice skills of social work, skill 3 (Identifying and problem-solving skills have a strong influence on the remaining skills). The correlation scores are fairly high are $0.72,0.87,0.88$ and 0.89 , respectively for the information collection and processing skills, the client access and assessment skills, the skills of connecting resources and making support plans, the self-test and selfassessment skills. This result shows that if the training institution equips students of social work with good skills of identifying and solving problems, this will greatly help students in the internship. From the perspective of social work theory, when the social workers identify the problems of their clients correctly, the remaining tasks in process of supporting clients will be made easier. The ecological system theory states that whenever an individual's problem is properly and appropriately identified, information gathering or seeking assistance will be simpler and more effective [14]. In summary, the results in table 2 point out that 05 professional practice skills of social work have a close correlation.

\section{Conclusion}

The college students' performance of professional practice skills of social work during the internship initially is quite well. Students were able to perform the assigned tasks on their internship. The professional practice skills well performed by students are the client access and assessment and self-test and self-assessment skills. The skills that students did not perform well are connecting resources and making support plans skills. Therefore, the subjects related to client support services should be paid attention to in the training program. Training institutions should also strengthen 
exchanges between social work experts and students to help students improve their professional skills better

It is necessary to have many measures to improve professional skills for students, in which focusing on sending students to social work establishments in the internship and during the process of learning specialized subjects [15]. The practice should be guided by experienced and professional trainers to promptly help students solve problems encountered in professional internships.

\section{References}

[1] Proceeding of the scientific conference (2016). Building a training program for social work to meet social needs. Ho Chi Minh City College of Central Pedagogy.

[2] Farley, O. W. \& Smith, L. L. (2006). Introduction to Social Work. (10th edition). Boston: Pearson.

[3] Vayda, E., \& Bogo, M. (1991). A teaching model to unite classroom and field. Journal of Social Work Education, 27 (3), 271-278.

[4] Munro, E. (2002). The role of theory in social work research: A future contribution of the debate. Journal of Social Work Education, 38 (3), 461-470.

[5] Nguyen Huu Long (2019). Professional practice skills of college students in Social Work, Ministry-level Education and Training project.
[6] Welford, A. T. (1958) Aging and Human Skills, London, Oxford University Press.

[7] Trevithick, P., Richards, S., Ruch, G. and Moss, B. (2004) Teaching and LearningCommunication Skills in Social Work Education. London, Social Care Institute forExcellence

[8] Cree, V. (2003). Becoming a social worker. London: Routledge

[9] Thompson, N. (2000). Understanding social work: Preparing for practice. Basingstock: Macmillan

[10] Rwomire, A. \& Raditlhokwa, L. (1996). Social Work in Africa: Issues and Challenges. Journal of Social Development in Africa 2, 5-19

[11] Morales, A. T., Sheafor, B. W. \& Scott, M. E. (2011). Social work: a profession of many faces (Updated edition) (12th Edition) (Connecting core competencies). Columbus, $\mathrm{OH}$ : Prentice Hall.

[12] Nguyen Van Luc (2017). Skills to establish social relationships in practice and internship of students of some Universities in Ho Chi Minh City. Master thesis.

[13] Dang Thi Huyen Oanh (2015). The need to build practice models of social work. Master thesis. Hanoi University of Pedagogy.

[14] Le Chi An (2004, 2006). Personal Social Work. Ho Chi Minh City Open University, Faculty of Sociology.

[15] Nguyen Minh Chau (2004). Solutions to improve professional practice skills for college students in agricultural engineering. $\mathrm{PhD}$ thesis in Education Studies, Hanoi. 